\title{
Simulation Analysis of Thermal Insulation Performance of PCM for Mitigating Urban Heat Island Effect
}

\author{
Hyo Eun Lee ${ }^{1}$, Young Kwon Yang ${ }^{1}$, Min-Hee Chung 2 , Jin Chul Park ${ }^{2}$ \\ ${ }^{1}$ School of Architectural Engineering, Chung-Ang University \\ 84, Heukseok-ro, Dongjak-gu, Seoul, Republic of Korea \\ bell3457@gmail.com; dora84@ naver.com \\ ${ }^{2}$ School of architecture \& Building Science, Chung-Ang University \\ 84, Heukseok-ro, Dongjak-gu, Seoul, Republic of Korea \\ mhloveu81@naver.com; jincpark@cau.ac.kr
}

\begin{abstract}
This study aimed to analyze the Thermal Insulation Performance of the PCM Cool Roof System, which is being developed for mitigating the Urban Heat Island Effect. We compared the performance of general insulation material versus that of PCM, both applied on a standard roof model. General insulation material contained 50mm Expanded Poly Styrene, 135mm Expanded Poly Styrene, and $135 \mathrm{~mm}$ cellulose. We found that PCM had less cooling energy consumption compared to general insulation, whereas general insulation had less heating energy consumption. The annual total energy consumption was found to be lower when using PCM. Therefore, we conclude that the PCM Cool Roof System has insulating capacity comparable to that of general insulation. And its thermal insulation performance is similar or better compared with general insulation, although thermal conductivity of PCM in solid status is generally $0.24 \mathrm{~W} / \mathrm{mK}$ which almost eight times higher than general insulation.
\end{abstract}

Keywords: Phase Change Materials(PCM), Energy Plus Simulation, Insulation Performance, Cooling \& Heating Energy Consumption

\section{Introduction}

\subsection{Background and Purpose of Study}

Urban heat island effect refers to high temperatures in the downtown areas where structures with relatively high heat storage performance are concentrated. In South Korea, the urban heat island effect is emerging as a serious environmental problem due to the urban development around large cities such as Seoul, the capital area, and metropolitan cities through compressed economic growth and the subsequent concentration of population.

Consequently, our research team conducted the "Experiment on the Performance of PCM and Cool Roof System for Mitigating Urban Heat Island" as a precedent study, and verified the mitigating effect of urban heat island effect by applying a phase change material (PCM) to an existing building.

However, the thermal insulation performance of PCM applied as the roof finishing material of existing buildings has not been verified yet. Thermal insulation is very important to reduce the energy consumption of a building. The thermal insulation effect of PCM is essential from the aspect of buildings because it is a system that is additionally applied to the building finishing materials.

In this study, therefore, the applicability of PCM to building finishing materials was derived through energy simulation analysis to examine the thermal insulation performance of PCM.

\subsection{Scope and Method of Study}

The scope of this study is to analyze the thermal insulation performance of PCM through an analysis of simulation results for office and residence standard models. The target of the energy simulation standard model was set as an existing building considering that the PCM Cool Roof System is targeted at existing buildings. The flow of this study is as follows, and the flowchart is shown in Fig. 1. 
First, previous studies and theories were considered to examine the thermal insulation performance of PCM as a building finishing material and to conduct energy simulation analysis. Second, the indoor energy consumptions were comparatively examined between the case where PCM was additionally applied to the roof of an existing building and the case where a general thermal insulation material was additionally applied to the roof using the energy simulation application EnergyPlus ver. 8.1 which was developed by the U.S. Department of Energy. Third, the applicability of PCM was determined based on the derived thermal insulation performance result of PCM.

\begin{tabular}{|c|c|c|c|c|}
\hline \multicolumn{2}{|c|}{ Examination of previous studies } & \multicolumn{2}{|c|}{ EnergyPlus Simulation } & Analysis of simulation results \\
\hline \multirow{2}{*}{$\begin{array}{l}\text { Application of } \\
\text { PCM to } \\
\text { Buildings }\end{array}$} & \multirow{2}{*}{$\begin{array}{l}\text { Thermal } \\
\text { insulation } \\
\text { materials }\end{array}$} & \multicolumn{2}{|c|}{$\begin{array}{l}\text { Comparison of general } \\
\text { thermal insulation materials } \\
\text { and PCM }\end{array}$} & \multirow{2}{*}{$\begin{array}{l}\text { Analysis of the thermal } \\
\text { insulation performance of } \\
\text { PCM through comparison with } \\
\text { general thermal insulation } \\
\text { materials }\end{array}$} \\
\hline & & OFFICE & RESIDENCE & \\
\hline
\end{tabular}

Fig. 1: Study Flowchart.

\section{Discussion of Previous Studies}

\subsection{Application of PCM to Buildings}

An examination of previous studies on the thermal performance of PCM applied to buildings revealed that PCM was effective in mitigating urban heat island effect and improving indoor comfort.

Bang (2016) conducted a scaled model test that measured the surface reflectance when PCM was inserted in a building roof structure, the surface temperature reduction effect by PCM type, and the thermal performance of PCM on structures. The experiment results showed that the application of PCM under the identical reflectance, ambience condition, and solar radiation decreased the surface temperature by approximately $10^{\circ} \mathrm{C}$.

According to Kim et al. (2011), applying PCM that causes phase change in a comfortable temperature range as felt by occupants can produce great effects in terms of energy, reduce environmental load, and guarantee the comfort of occupants.

Jiawei Lei et al. (2016) used Energy Plus ver.8.1 to study the reduction of cooling load, and conducted numerical analysis according to the ambient condition of the building, phase change, temperature, location, and the thickness of PCM.

Many studies have been conducted of the excellence of PCM and its contribution to the improvement of the comfort of occupants, but no studies have discussed the thermal insulation of PCM, and this is the reason that this study was conducted.

\subsection{Thermal Insulation Performance of Buildings}

Kim (1996) studied on the change of thermal performance according to the thermal insulation method applied to the outer walls of buildings. The heat conductivity varies by the use or no use of thermal insulation material, the thickness of the thermal insulation material, and the characteristics of the finishing material. Furthermore, the resistance of heat conductivity of walls is identical and the annual cooling and heating loads are almost identical if they are made of the same material and have the same thickness. In other words, theoretically, the energy saving effect does not vary by the interior and exterior insulation. Thus, the simulation model prepared in this study does not consider the difference in thermal performance by the location of thermal simulation materials. 


\section{Outline of the Simulation to Compare Indoor Energy Consumption between PCM and General Thermal Insulation Materials}

\subsection{Outline of Simulation}

The analysis model for evaluating the thermal insulation performance was created using Design Builder, an integrated construction simulation tool developed by Design Builder Software Ltd. in the UK, and the energy performance was evaluated by using the energy simulation program EnergyPlus ver. 8-5 developed by the U.S. Department of Energy. To analyze the thermal performance when applied to existing buildings, the Regulation for the Standards of Building Facilities, etc., 1992 was used. Thus, the heat conductivity of the wall and floor was set at $0.5 \mathrm{kcal} / \mathrm{m}^{2} \mathrm{~h}^{\circ} \mathrm{C}$, and that of the roof was set at $0.35 \mathrm{kcal} / \mathrm{m}^{2} \mathrm{~h}^{\circ} \mathrm{C}$. In addition, PCM and general thermal insulation materials were applied to the roof and the changes in cooling and heating energy consumption were compared between the two types of materials.

For climate date, the average year data (1981-2010) of Seoul for 30 years by the Korea Meteorological Administration was used.

\subsection{Simulation Variables}

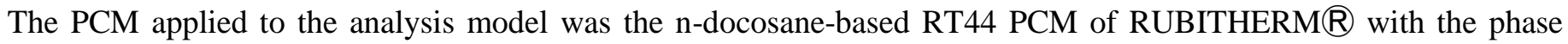
change temperature (melting point) of $44^{\circ} \mathrm{C}$. For the control group, three types and thicknesses of thermal insulation materials in general use were selected. The first is $50 \mathrm{~mm}$ expanded polystyrene (EPS) which had been most frequently used in 88 buildings with 10 or higher stories built in 1980s and 1990s in South Korea, and has a thermal conductivity of $0.04 \mathrm{~W} / \mathrm{mk}$ (Kim, 1996). The second one is $135 \mathrm{~mm}$ EPS which is mainly used for roof insulation of multi-dwelling houses and has the same thermal characteristics as those of the first one (Park, 2013). The third one is cellulose 135mm which has a high density, is relatively environment-friendly. And has a thermal conductivity of $0.04 \mathrm{~W} / \mathrm{mk}$. The thickness was set at $135 \mathrm{~mm}$, which is identical to that of the second and third ones. The simulation was conducted by applying these three general thermal insulation materials to a roof with a heat conductivity of $0.35 \mathrm{kcal} / \mathrm{m}^{2} \mathrm{~h}^{\circ} \mathrm{C}$ and RT $44 \mathrm{PCM}$ in thicknesses corresponding to those of the general thermal insulation materials.

Table 1: Types and thicknesses of general thermal insulation materials versus PCM.

\begin{tabular}{|c|c|c|}
\hline & General thermal insulation materials & PCM \\
\hline 1 & $50 \mathrm{~mm}$ Styrofoam (bead method, EPS) & $50 \mathrm{~mm}$ RT44 PCM \\
\hline 2 & $135 \mathrm{~mm}$ Styrofoam (bead method, EPS) & $135 \mathrm{~mm}$ RT44 PCM \\
\hline 3 & $135 \mathrm{~mm}$ cellulose & $135 \mathrm{~mm}$ RT 44 PCM \\
\hline
\end{tabular}

The analysis model is defined with the two cases of office and residential with different factors influencing energy load such as occupancy schedule, cooling and heating air condition systems, and size. The analysis model settings of each case are listed in Table 2.

The specifications of the analysis model referred to previous studies and ASHRAE 62.1, and the heat conductivity was based on the Regulation for the Standards of Building Facilities, etc., which was revised in 1992, to provide similar conditions as those of existing buildings. As the office HVAC system is a fan coil unit (4-pipe) which can provide cooling, heating, and mechanical ventilation, cooling and heating energy consumptions are generated in four seasons. On the other hand, the residential HVAC system consists of floor heating boilers and the cooling method of air conditioning in most apartment and detached houses in South Korea, thus generating cooling and heating energy consumptions separately in summer and winter. 
Table 2: Analysis Model and Settings by Case.

\begin{tabular}{|c|c|c|}
\hline Case & Office & Residence \\
\hline Size & $\begin{array}{c}\text { Area: } 288 \mathrm{~m}^{2} \\
\text { Story height: } 4 \mathrm{~m}\end{array}$ & $\begin{array}{c}\text { Area: } 85 \mathrm{~m}^{2} \\
\text { Story height: } 2.6 \mathrm{~m}\end{array}$ \\
\hline $\begin{array}{l}\text { Heat transmittance } \\
\text { (U-value) }\end{array}$ & \multicolumn{2}{|c|}{ Walls and floors: $0.5 \mathrm{kcal} / \mathrm{m}^{2} \mathrm{~h}^{\circ} \mathrm{C}$} \\
\hline Window area ratio & \multicolumn{2}{|c|}{$30 \%$} \\
\hline HVAC System & $\begin{array}{c}\text { Fan Coil Unit(4-Pipe) with District } \\
\text { Heating+Cooling }\end{array}$ & Heated floor, Boiler HW, Nat Vent \\
\hline Occupation schedule & $\begin{array}{c}\text { ASHRAE } 62.1 \text { - Office Buildings - } \\
\text { Office-Open Plan }\end{array}$ & $\begin{array}{c}\text { ASHRAE } 62.1 \text { - Residential - Dwelling } \\
\text { unit (with kitchen) }\end{array}$ \\
\hline
\end{tabular}

\section{Comparison Results of Indoor Energy Consumption between PCM and General Thermal Insulation Materials}

\subsection{0mm EPS (Expanded Poly Styrene) vs. 50mm RT44 PCM}

1) Office

The application results of the $50 \mathrm{~mm}$ EPS which had been most frequently used in 88 buildings with 10 or higher stories built in 1980s and 1990s in South Korea and $50 \mathrm{~mm}$ RT44 PCM with the same thickness to a roof with a heat conductivity of $0.35 \mathrm{kcal} / \mathrm{m}^{2} \mathrm{~h}^{\circ} \mathrm{C}$ are as follows. When the EPS was applied, the annual cooling energy consumption was $26757.26 \mathrm{kWh}$, the annual heating energy consumption was $13443.58 \mathrm{kWh}$, and the total was $40200.84 \mathrm{kWh}$. When the PCM was applied, the annual cooling energy consumption was $26744.01 \mathrm{kWh}$, and the annual heating energy consumption was $26744.01 \mathrm{kWh}$, and the total was $38503.51 \mathrm{kWh}$. When the PCM was applied, the cooling energy consumption was lower by $13.25 \mathrm{kWh}$ and the heating energy consumption of was lower by $1684.08 \mathrm{kWh}$; thus, the total energy consumption was lower by $1697.33 \mathrm{kWh}$.

2) Residence

When 50mm EPS was applied to the residence, the annual cooling energy consumption was $7021.361 \mathrm{kWh}$, the annual heating energy consumption was $1593.82 \mathrm{kWh}$, and the total consumption was $8615.18 \mathrm{kWh}$. When the PCM was applied, the annual cooling energy consumption was $6463.96 \mathrm{kWh}$, the annual heating energy consumption was $1971.39 \mathrm{kWh}$, and the total consumption was $8435.35 \mathrm{kWh}$. In other words, the cooling energy was saved by $557.4 \mathrm{kWh}$ when the PCM was applied, and the heating energy was saved by $377.57 \mathrm{kWh}$ when the EPS was applied. As a result, the use of PCM saved $179.83 \mathrm{kWh}$ in total annual cooling and heating energy consumptions. 


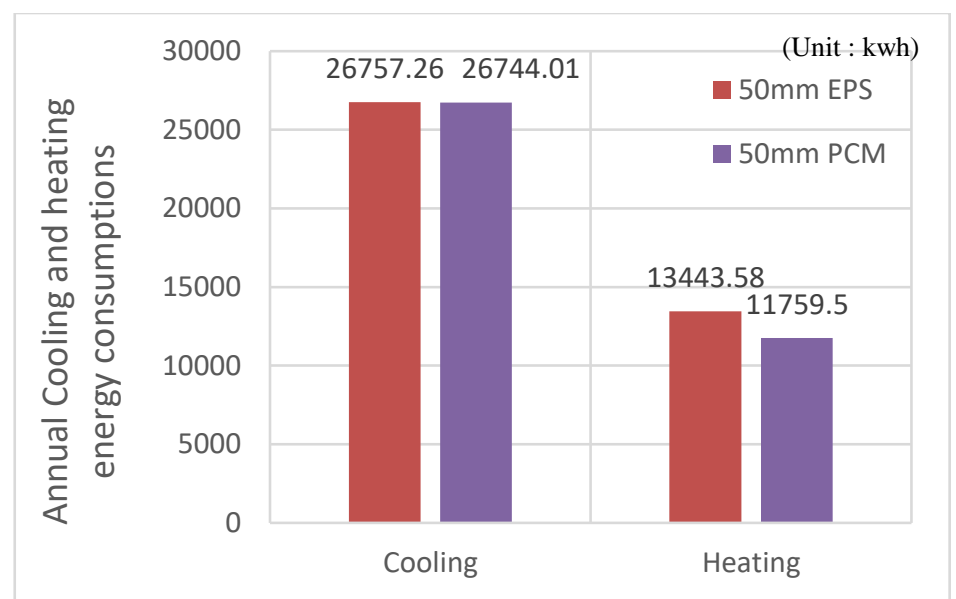

Fig. 2: Cooling and heating energy consumptions with 50mm EPS and 50mm PCM in Office.

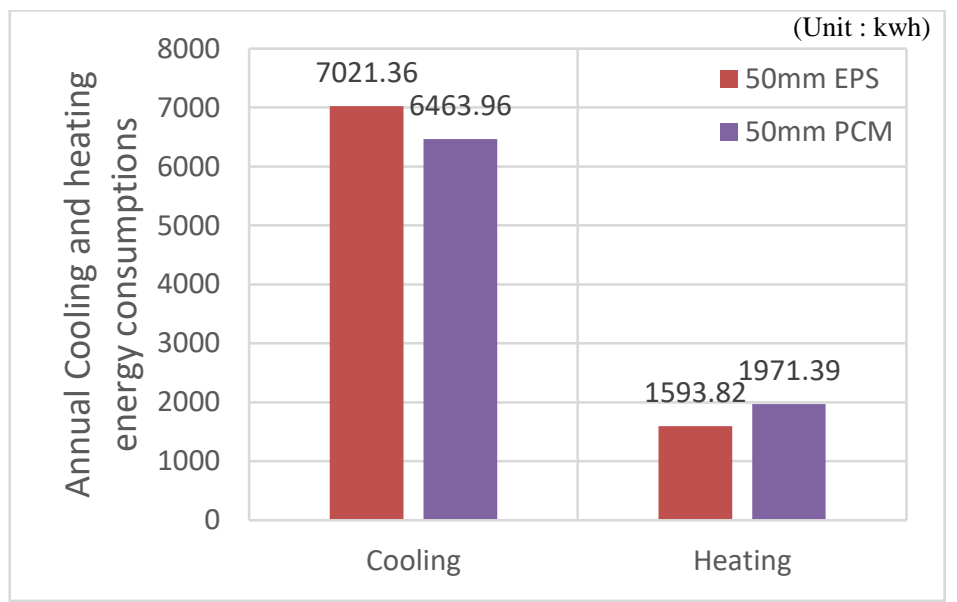

Fig. 3: Cooling and heating energy consumptions with 50mm EPS and 50mm PCM in Residence.

\subsection{5mm EPS (Styrofoam) vs. 135mm RT44 PCM}

1) Office

The application of thermal insulation materials is being strengthened recently with the gradually intensifying building energy saving standards. According to a survey of small design offices in 2013, the most frequently used thermal insulation material for roof is $135 \mathrm{~mm}$ EPS (Park. et al. 2013). The comparison results between the application of $135 \mathrm{~mm}$ EPS and PCT are as follows.

When EPS was applied, the annual cooling energy consumption was $29127.95 \mathrm{kWh}$ and the annual heating energy consumption was $11873.53 \mathrm{kWh}$. When PCM was applied, the annual cooling energy consumption was $26696.53 \mathrm{kWh}$ and the annual heating energy consumption was $12825.57 \mathrm{kWh}$. Thus, from the aspect of cooling energy consumption, PCM is advantageous by $2431.42 \mathrm{kWh}$, and from the aspect of heating energy consumption, EPS is advantageous by $952.03 \mathrm{kWh}$. The total annual cooling and heating energy consumption is $41001.49 \mathrm{kWh}$ for EPS and $39522.1 \mathrm{kWh}$ for PCM. Thus, PCM is advantageous by $1479.39 \mathrm{kWh}$ over EPS. 


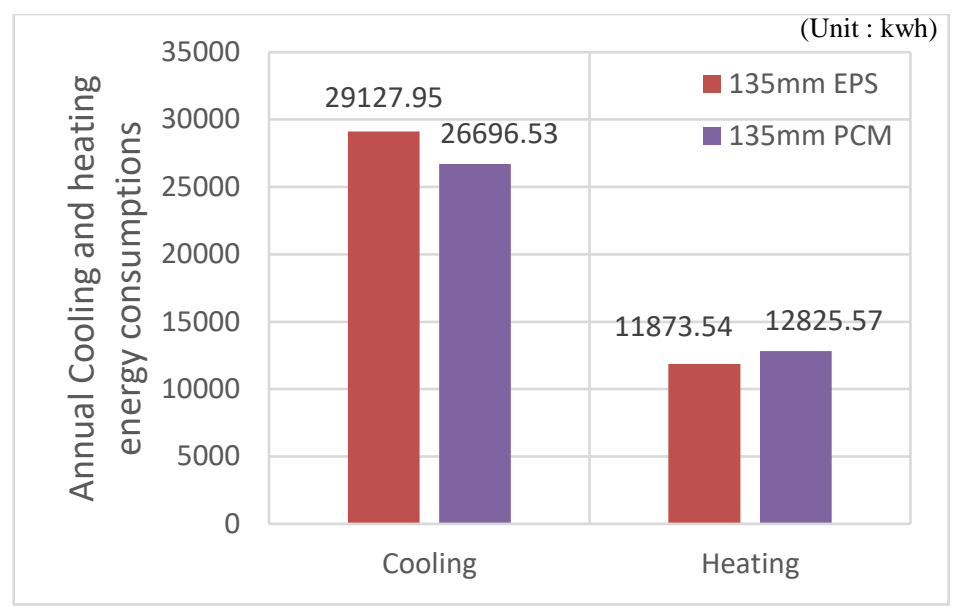

Fig. 4: Cooling and heating energy consumptions with 135mm EPS and 135mm PCM in Office.

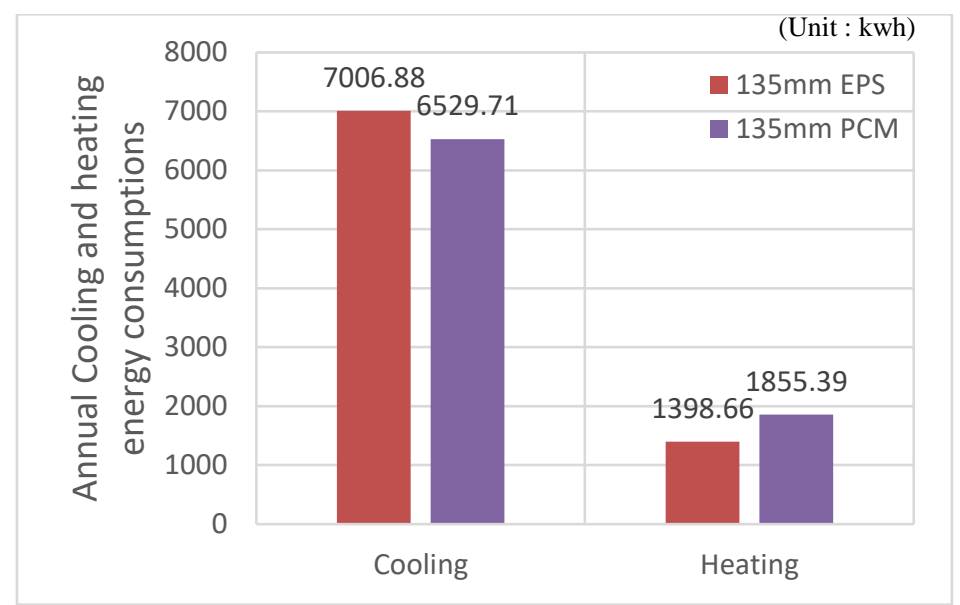

Fig. 5: Cooling and heating energy consumptions with $135 \mathrm{~mm}$ EPS and 135mm PCM in Residence.

\section{2) Residence}

The application results of residence were similar to those of office. The cooling energy consumptions of the EPS and PCM application cases were $7006.88 \mathrm{kWh}$ and $6529.71 \mathrm{kWh}$, respectively. Thus, the PCM application saved the energy of $477.17 \mathrm{kWh}$. On the other hand, the heating energy consumptions of the EPS and PCM application cases were 1398.66kWh and $1855.39 \mathrm{kWh}$, respectively. Thus, the EPS application saved the energy of $456.73 \mathrm{kWh}$. Thus, the difference in total annual cooling and heating energy consumption was $20.44 \mathrm{kWh}$ and the PCM was slightly advantageous.

\subsection{5mm Cellulose vs. $135 \mathrm{~mm}$ RT44 PCM}

\section{1) Office}

Cellulose is a thermal insulation material produced by recycling paper such as newspaper and is classified as an environment-friendly insulation material because it has three times greater density than that of fiberglass and does not generate toxic gas when it is burned. The thermal insulation performance was compared and analyzed between cellulose and PCM with the same thickness as described in section 4.2.

Cellulose consumed less cooling and heating energy by $581.02 \mathrm{kWh}$ and $143.99 \mathrm{kWh}$, respectively compared to EPS with the same thickness. However, the PCM with the same thickness consumed $26696.53 \mathrm{kWh}$ in cooling energy and $12825.57 \mathrm{kWh}$ in heating energy, with a total cooling and heating energy consumption of $39522.1 \mathrm{kWh}$. Thus, PCM saved the energy of $754.38 \mathrm{kWh}$ compared to cellulose. As with the case in the previous section, cellulose is advantageous from the aspect of cooling energy consumption and PCM is advantageous from the aspect of heating energy consumption. 
2) Residence

When the applications of cellulose and PCM to residence were compared, the total annual cooling and heating energy consumptions of cellulose and PCM were $8384.36 \mathrm{kWh}$ and $8385.1 \mathrm{kWh}$, respectively. Thus, the cellulose application consumed less energy, but the difference was only $0.74 \mathrm{kWh}$. Thus, they were almost identical. The cooling energy consumption was $6529.71 \mathrm{kWh}$ for PCM and 6955.91kWh for cellulose. Thus, PCM was advantageous by $426.2 \mathrm{kWh}$. However, the heating energy consumption of cellulose was lower by $426.94 \mathrm{kWh}$ compared to PCM. Thus, cellulose was slightly advantageous from the aspect of total annual cooling and heating energy consumption.

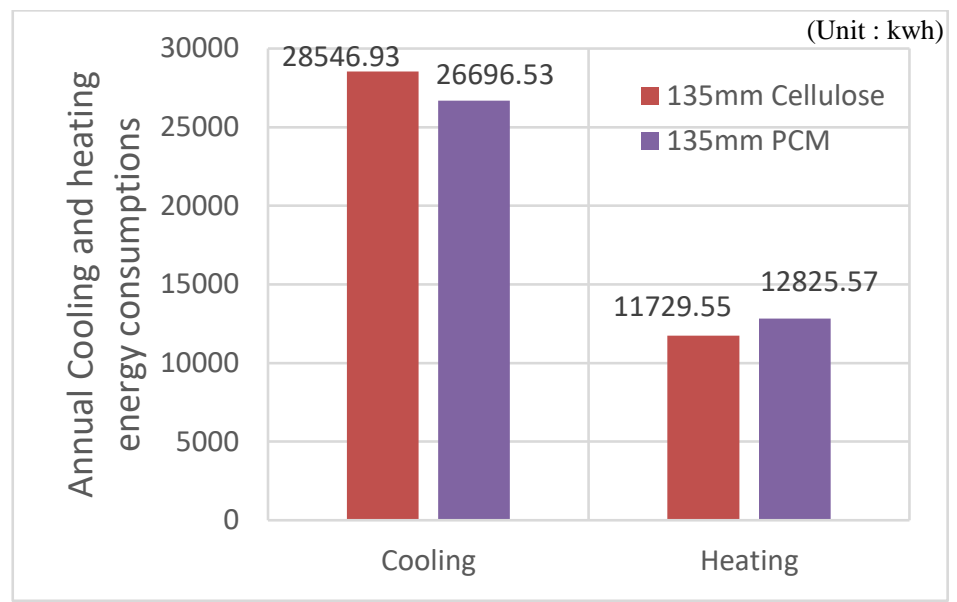

Fig. 6: Cooling and heating energy consumptions with 135mm EPS and 135mm PCM in Office.

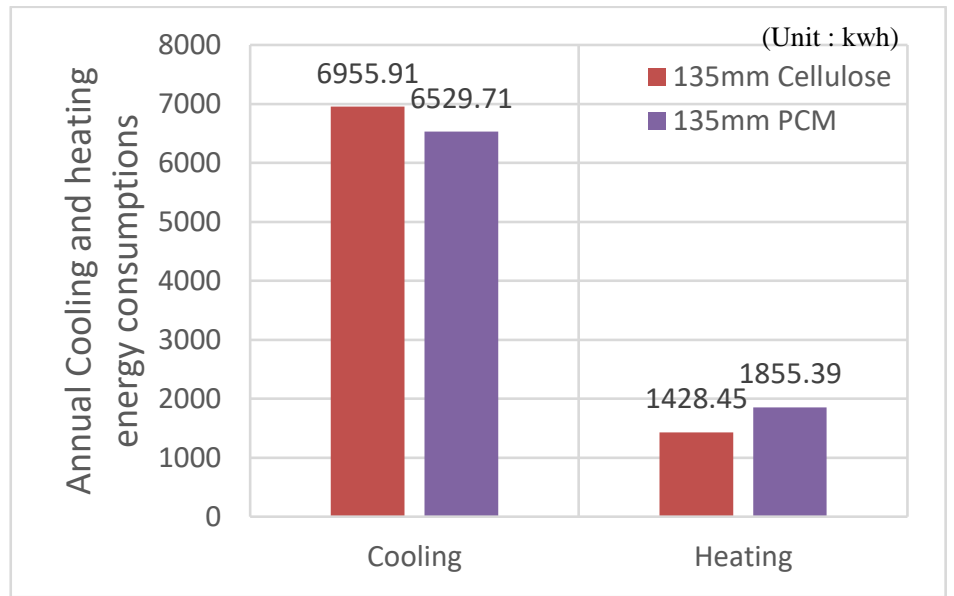

Fig. 7: Cooling and heating energy consumptions with 135mm EPS and 135mm PCM in Residence.

\subsection{Comparison of EPS, Cellulose and PCM}

The annual cooling and heating energy consumptions were compared among EPS, cellulose, and PCM with the same thickness. PCM was lower in the cooling energy consumption for both office and residence, but the general thermal insulation materials showed lower heating energy consumptions than that of PCM. The differences in total annual cooling and heating energy consumptions were small, less than $21 \mathrm{kWh}$, and the consumption of PCM was smaller.

1) Office

The PCM showed the lowest cooling energy consumption of $26696.53 \mathrm{kWh}$, but the highest heating energy consumption of $12825.57 \mathrm{kWh}$. The total energy consumption of PCM was $39522.1 \mathrm{kWh}$, which was also the lowest. The difference of PCM with EPS and cellulose were 1479.39kWh, 754.38kWh, and 1255.49kWh.

2) Residence 
As with the office, PCM showed a lower cooling energy consumption and the general thermal insulation materials showed a lower heating energy consumption. The total energy consumption of PCM was $8385.1 \mathrm{kWh}$, which was higher by $20.44 \mathrm{kWh}$ than that of EPS, and it was lower by $0.74 \mathrm{kWh}$ than that of cellulose.

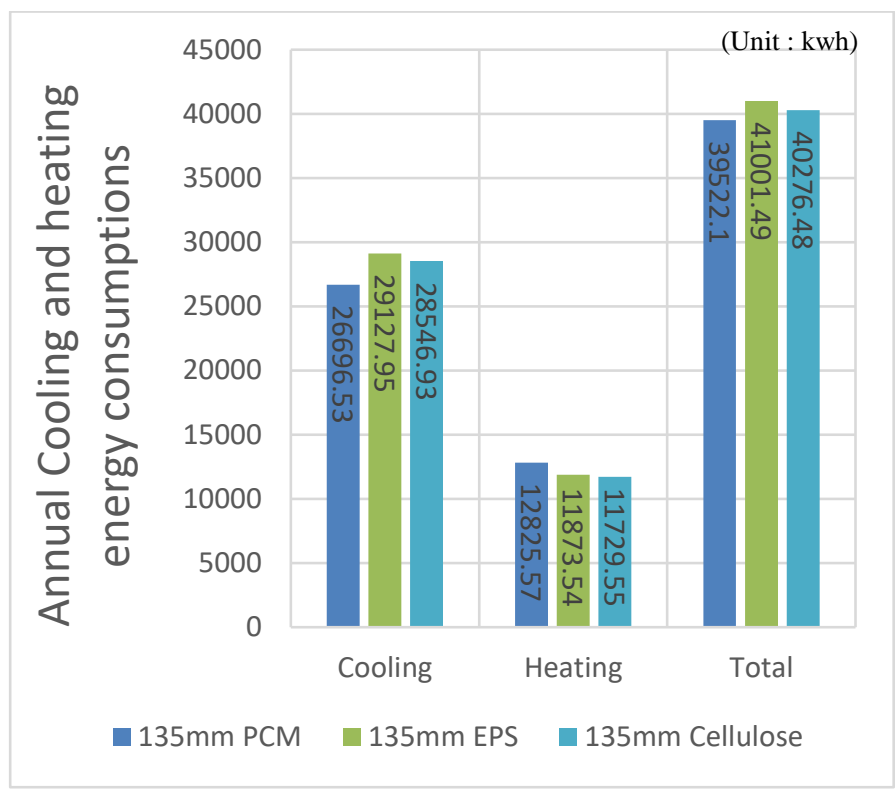

Fig. 8: Comparison of EPS, Cellulose, and PCM (Office).

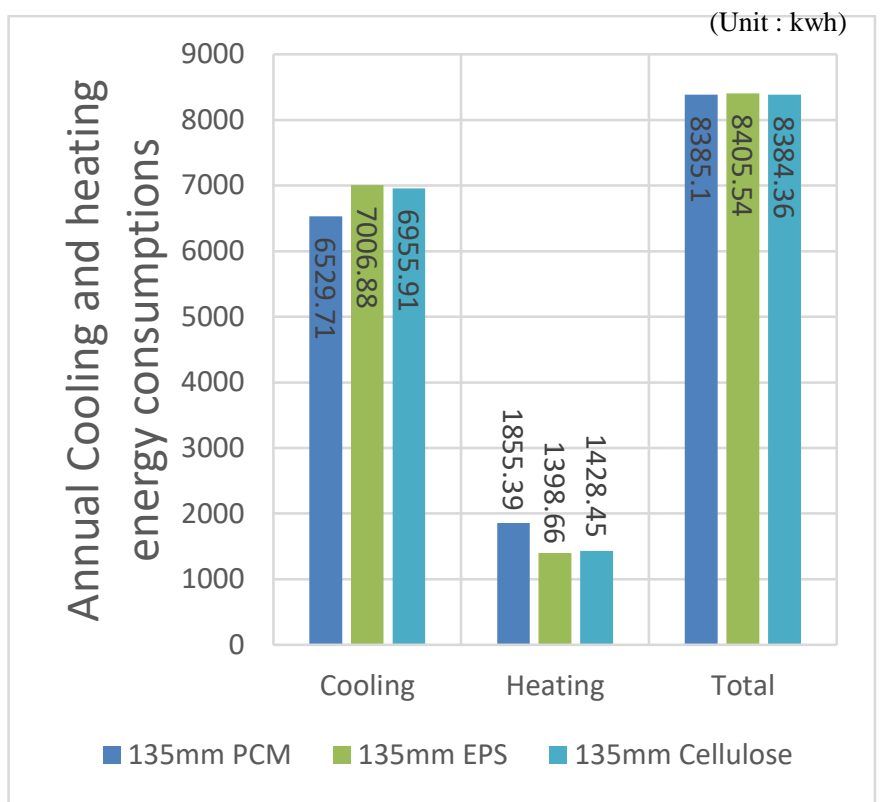

Fig. 9: Comparison of EPS, Cellulose, and PCM (Residence). 


\section{Conclusion}

In this study, simulation analysis was conducted to analyze the thermal insulation performances of PCM applied to the PCM Cool Roof System for mitigating urban heat island effects. The main findings of this study are as follows:

(1) For the $135 \mathrm{~mm}$ thickness of PCM, the RT 44 PCM was advantageous from the aspect of cooling energy consumption and disadvantageous from the aspect of heating energy consumption.

(2) The reason for these results seem to be due to the fact that the thermal conductivity of RT44 PCM in sold state is approximately $0.24 \mathrm{~W} / \mathrm{mK}$, which is higher than that of general thermal insulation materials by around 8 -fold and that the composition of solid and liquid varies by the solar radiation and the thickness of PCM.

(3) The total annual cooling and heating energy consumption of PCM was similar to or smaller than those of general thermal insulation materials. Thus, PCM is advantageous for energy saving.

(4) Therefore, the thermal insulation performance of PCM that is applied to the PCM Cool Roof System for mitigating urban heat island effects was comparable to that of general thermal insulation materials and the applicability of PCM as building finishing material was verified.

\section{References}

[1] Korea Research Institute of Human Settlements, A Study on the Housing Market by Region, 1986.

[2] S. K. Bang, "A scaled model test of thermal performance using PCM for mitigating urban heat island effect," M. S. thesis, Chung-Ang University Graduate School, Department of Architectural Engineering, Building Equipment and Energy Major, 2016.

[3] S. K. Jeong, et al., "Consideration for Application of Phase Change Material (PCM) for Building Energy Saving," Journal of Korean Institute of Architectural Sustainable Environment and Building System, 2011, vol. 5, no. 1.

[4] L. Jiawei, et al., "Energy performance of building envelopes integrated with phase change materials for cooling load reduction in tropical Singapore," Applied Energy, 2016, vol. 162, pp 207-217.

[5] J. H. Kim, "A study on the thermal performance evaluation of the exterior wall for the insulating methods in building $=$ focused on the usage of building," M. S. thesis, Suwon University Graduate School, Department of Architectural Engineering, 1996.

[6] S.J. Park, et al., "A study on Design Current State and Optimization of Envelope Composition of Multi-Family Housing," Journal of Architectural Institute of Korea, 2013, vol. 15, no. 2. 